\title{
Structure and Properties of Ti/TiB Metal-Matrix Composite after Isothermal Multiaxial Forging
}

\author{
S. Zherebtsov*, M. Ozerov, N. Stepanov and M. Klimova \\ Belgorod State University, Pobeda-85, Belgorod 308015, Russia
}

\begin{abstract}
Microstructure and mechanical properties of a $\mathrm{Ti} / \mathrm{TiB}$ metal-matrix composites after multiaxial forging at $850{ }^{\circ} \mathrm{C}$ to the true strain $\varepsilon=5.2$ were studied. The composite with 17 vol. $\%$ of $\mathrm{TiB}$ was produced via spark plasma sintering at $1000^{\circ} \mathrm{C}$. Mechanical behavior in terms of aggregated $\sigma-\Sigma \varepsilon$ curves during the multiaxial forging demonstrated a pronounced softening following by a steady-like flow stage. The length of TiB whiskers considerably decreased after the first step of the multiaxial forging and then changed insignificantly. The microstructure after the MAF consisted of dislocation-free Ti matrix areas of $\approx 1 \mu \mathrm{m}$ in diameter and areas with high density of TiB whiskers and high dislocation density. The forging resulted in a considerable increase in ductility of the $\mathrm{Ti} / \mathrm{TiB}$ metal-matrix composites at room and elevated temperatures without loss in strength.
\end{abstract}

DOI: 10.12693/APhysPolA.134.695

PACS/topics: 81.20.Ev, 81.40.Gh, 81.40.Lm, 81.70.Bt

\section{Introduction}

One of the attractive way to increase strength-related properties (strength, hardness, wear resistance, etc.) in titanium and low-alloyed titanium alloys is associated with creating Ti matrix composites with embedded ceramic reinforcements by, for example, spark plasma sintering (SPS) technology [1-3]. Among various reinforcements $\mathrm{TiB}$ has a close to titanium density, it creates minimal residual stresses and has good crystallographic interface with the Ti matrix $[4,5]$. During the SPS the TiB whiskers form as a result of the chemical reaction $\mathrm{Ti}+\mathrm{TiB}_{2}=\mathrm{Ti}+2 \mathrm{TiB}$. However, along with the increased strength, $\mathrm{Ti} / \mathrm{TiB}$ metal-matrix composites (MMCs) demonstrate poor low-temperature ductility. Mechanical properties of the MMCs can be improved by thermo-mechanical treatment, for example multiple isothermal 2D forging (drawing) [6,7]. In this paper, microstructure and mechanical properties of $17 \mathrm{vol} . \% \mathrm{TiB}$ reinforced titanium matrix composites produced by SPS at $1000{ }^{\circ} \mathrm{C}$ was studied after multiaxial forging at $850^{\circ} \mathrm{C}$ to $\varepsilon=5.2$.

\section{Materials and procedure}

Commercial $\mathrm{Ti}$ and $\mathrm{TiB}_{2}$ powders of $\approx 25$ and $\approx 4 \mu \mathrm{m}$ in diameter, respectively, were used as the raw materials. A mixture of $90 \mathrm{wt} \% \mathrm{Ti}$ and $10 \mathrm{wt} \% \mathrm{TiB}_{2}$ (which yields $17 \mathrm{vol} . \%$ of $\mathrm{TiB}$ during the reaction of $\mathrm{Ti}+\mathrm{TiB}_{2} \rightarrow \mathrm{Ti}+$ $2 \mathrm{TiB}$ [8]) was prepared using a Retsch RS 200 vibrating cup mill for $1 \mathrm{~h}$ in ethanol at the milling rotation speed of $700 \mathrm{rpm}$.

$\mathrm{Ti} / \mathrm{TiB} \mathrm{MMC}$ specimens measuring $15 \mathrm{~mm}$ in height and $19 \mathrm{~mm}$ in diameter were produced using the SPS process under vacuum on a Thermal Technology SPS 103 machine at $1000^{\circ} \mathrm{C}$ and $40 \mathrm{MPa}$ for $15 \mathrm{~min}$.

\footnotetext{
*corresponding author; e-mail: ser_z@mail.ru
}

The specimens were subjected to multiaxial forging (MAF) which comprised successive compressions of a sample along three orthogonal directions (this method is also known as "abc" deformation [9]). The initial strain rate and the true strain per deformation step were $10^{-3} / \mathrm{s}$ and $\approx 0.5$, respectively. Compressions were performed on an Instron 300LX testing machine in air at $850^{\circ} \mathrm{C}$. Stress-strain curves were recorded for each step. Ten compressions in total were made (the true cumulative strain $\Sigma \varepsilon \approx 5.2$ ).

A JEOL JEM-2100 transmission electron microscope (TEM) and a Quanta 600 FEG (field-emission-gun) scanning-electron microscope (SEM) were used for microstructure examination of the central region of the specimens. SEM specimens were etched using Kroll's reagent $\left(95 \% \mathrm{H}_{2} \mathrm{O}, 3 \% \mathrm{HNO}_{3}, 2 \% \mathrm{HF}\right)$

Tensile or compression tests were conducted on an Instron 5882 testing machine at $300^{\circ} \mathrm{C}, 400^{\circ} \mathrm{C}$, and $500^{\circ} \mathrm{C}$ (tensile) or room temperature (compression) at an initial strain rate of $10^{-3} / \mathrm{s}$. The tensile samples had the gauge measuring $4 \mathrm{~mm}$ length and $3 \mathrm{~mm} \times 1.5 \mathrm{~mm}$ crosssection. The compression specimens were measured as $6 \times 4 \times 4 \mathrm{~mm}^{3}$. Both the compression and tensile tests were carried out without extensometer mainly due to a very small gage size of the specimens.

\section{Results and discussion}

In the initial (as-sintered) condition the microstructure of the MMC consisted of $\mathrm{TiB}$ whiskers with the average diameter $63 \pm 35 \mathrm{~nm}$ heterogeneously distributed within the Ti matrix (Fig. 1). In the majority of the microstructure a very high dislocation density was observed most probably due to a large number of $\mathrm{TiB}$ particles. Some unreacted $\mathrm{TiB}_{2}$ particles (the volume fraction of $2 \%$ ) were observed in the microstructure. The residual porosity was $\approx 0.5 \%$.

True stress-true strain curves obtained during multiaxial isothermal forging at $850{ }^{\circ} \mathrm{C}$ showed an initial hard- 


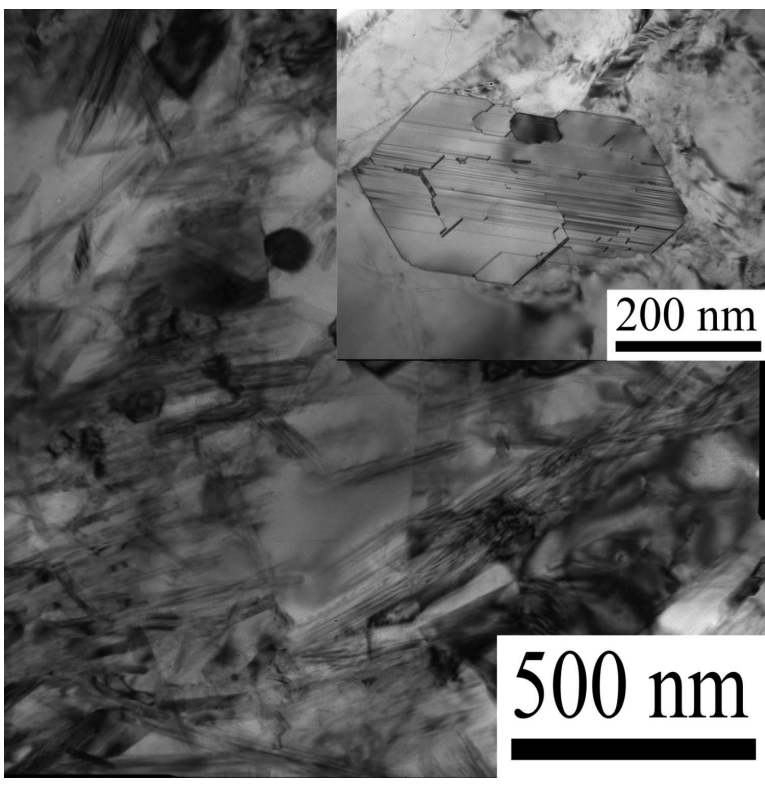

Fig. 1. Bright-field TEM image of Ti/TiB MMC microstructure; the inset shows a cross-section of a $\mathrm{TiB}$ whisker.

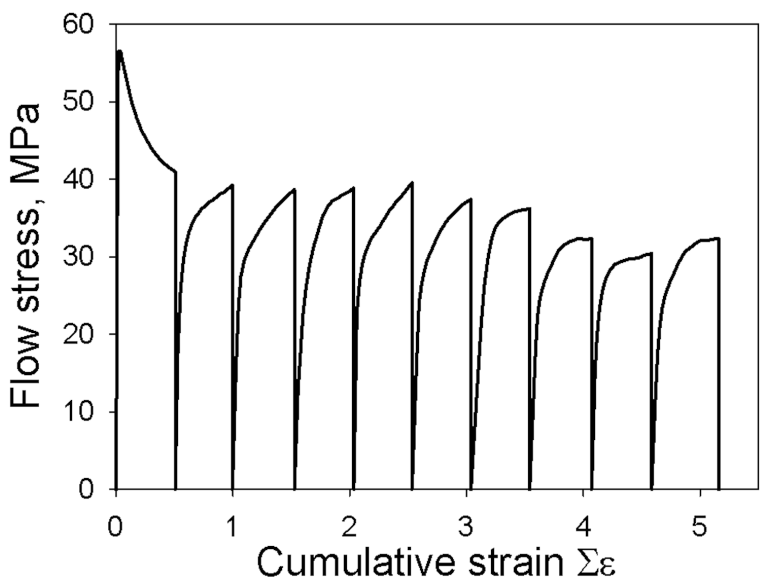

Fig. 2. True stress-true strain curves obtained during the MAF at $850^{\circ} \mathrm{C}$.

ening transient, a peak flow stress, and then flow softening during the first compression (Fig. 2). However at late stages $(\Sigma e>3)$ each stress-strain curve demonstrated a steady-state-like behavior after initial hardening. A noticeable difference between the flow stresses in the end of each step and the yield stress of the next step was observed. It should be noted also that the flow stress had a trend to decrease with increase of cumulative strain.

Microstructure of the $\mathrm{Ti} / \mathrm{TiB}$ metal-matrix composite changed considerably as a result of the MAF. A lot of small fragments of $\mathrm{TiB}$ were observed in the microstructure of the strained condition (Fig. 3a).

Meanwhile TEM analysis showed that deformation at $850^{\circ} \mathrm{C}$ to $e=5.2$ (10 steps) resulted in the formation of separate areas $(1-1.5 \mu \mathrm{m}$ in diameter) with a much lower dislocation density compared with the neighbor-
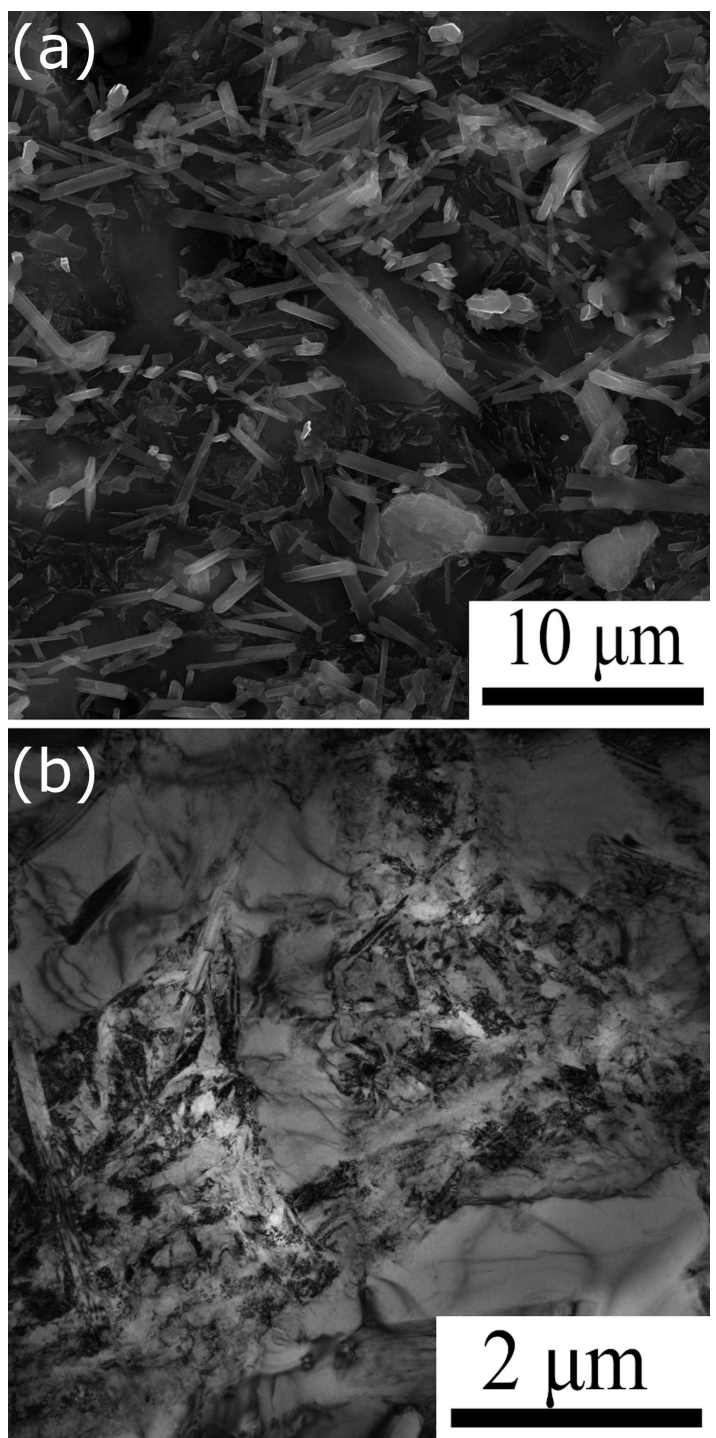

Fig. 3. SEM (a) and TEM bright-field (b) images of the $\mathrm{Ti} / \mathrm{TiB}$ composite after the MAF at $850{ }^{\circ} \mathrm{C}$ to $e=$ 5.2 (10 steps).

ing fields (Fig. 3b). The estimated dislocation density in these areas was $\approx 2 \times 10^{12} \mathrm{~m}^{-2}$. The boundaries of some dislocation-free areas can be well-defined. The development of recovery or recrystallization was more evident in the areas of the Ti matrix with a relatively low density of the TiB whiskers. The greater density of the TiB particles most likely hindered grain boundary movement thereby preserving the microstructure with a high dislocation density.

Quantitative analysis showed that the diameter of the whiskers did not noticeably change during the MAF. The apparent length of whiskers decreased considerably, by a factor of $\approx 3$, after the first step of the MAF and then remained almost unchanged during further deformation (Fig. 4). Thus, the length-to-diameter aspect ratio of TiB whiskers approached stable value $(\approx 10)$ at the initial stages of deformation and had not changed further. 


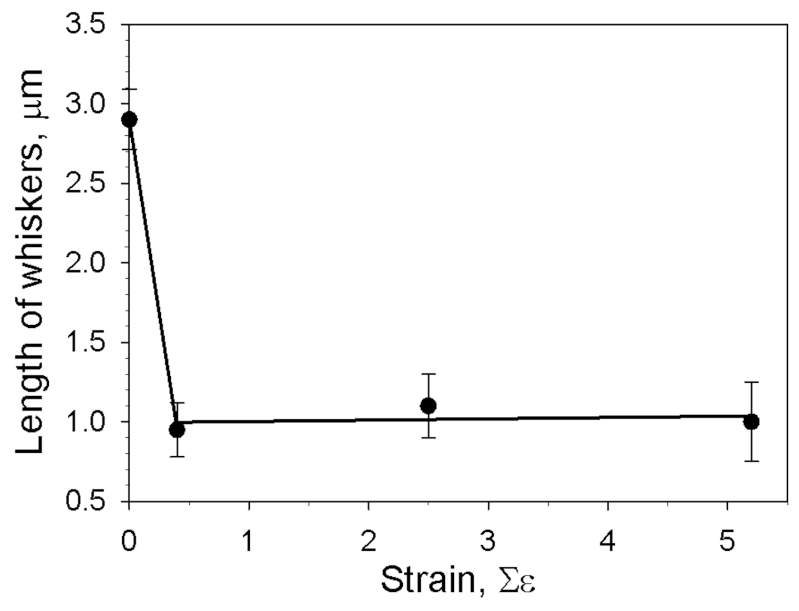

Fig. 4. Apparent length of $\mathrm{TiB}$ whiskers in $\mathrm{Ti} / \mathrm{TiB}$ MMCs during the MAF.

Mechanical behavior of the MMCs obtained in compression at room temperature (Fig. $5 \mathrm{a}$ ) or in tension at 300-500 ${ }^{\circ} \mathrm{C}$ (Fig. 5b) showed considerable improvement of ductility of the specimens after the MAF to $e=5.2(10$ steps) at $850^{\circ} \mathrm{C}$. The samples of the MMC after the MAF at $850^{\circ} \mathrm{C}$ demonstrated noticeable compression ductility $(\approx 2-3 \%)$ at room temperature and similar tensile ductility at $300{ }^{\circ} \mathrm{C}$. Meanwhile in the as-sintered condition the tensile specimen of MMC fractured just after the elastic region even at $400^{\circ} \mathrm{C}$. Some tensile elongation of the assintered composite was recorded only at $500{ }^{\circ} \mathrm{C}$. The ultimate compression strength of the forged and as-sintered specimens was quite similar at room temperature (2210 and $1960 \mathrm{MPa}$, respectively) while at elevated temperatures the specimens after the MAF became noticeably stronger. Quite a large stage of elasticity observed in all conditions of the MMC can be associated with the conducting of the tensile test without extensometer; in this case elastic deformation of the tensile machine parts was also included into the overall elastic deformation shown in the stress-strain diagram. In addition the Young modulus of the composite is not too high $(\approx 200 \mathrm{GPa}[4,10])$ while the yield stress at room temperature almost attained $2000 \mathrm{MPa}$.

After the MAF the ultimate strengths were found to be $765 \mathrm{MPa}$ at $300^{\circ} \mathrm{C}$ and $540 \mathrm{MPa}$ at $400^{\circ} \mathrm{C}$ while in the assintered condition the maximum attained strengths were $480 \mathrm{MPa}$ at $400^{\circ} \mathrm{C}$ and $520 \mathrm{MPa}$ at $500{ }^{\circ} \mathrm{C}$.

Therefore the results obtained in the current study show a possibility to increase considerably lowtemperature ductility without loss in strength of the $\mathrm{Ti} / \mathrm{TiB}$ MMCs by the multiaxial isothermal forging at $850{ }^{\circ} \mathrm{C}$ to $\varepsilon=5.2$. The observed improvement of the mechanical properties is most likely associated with the microstructure developed during the MAF. One of the most obvious effects of plastic deformation at elevated temperatures on the microstructure of $\mathrm{Ti} / \mathrm{TiB} \mathrm{MMC}$ was a considerable (by $\approx 3$ times) decrease in the length of the TiB whiskers. This change occurred in the very beginning of
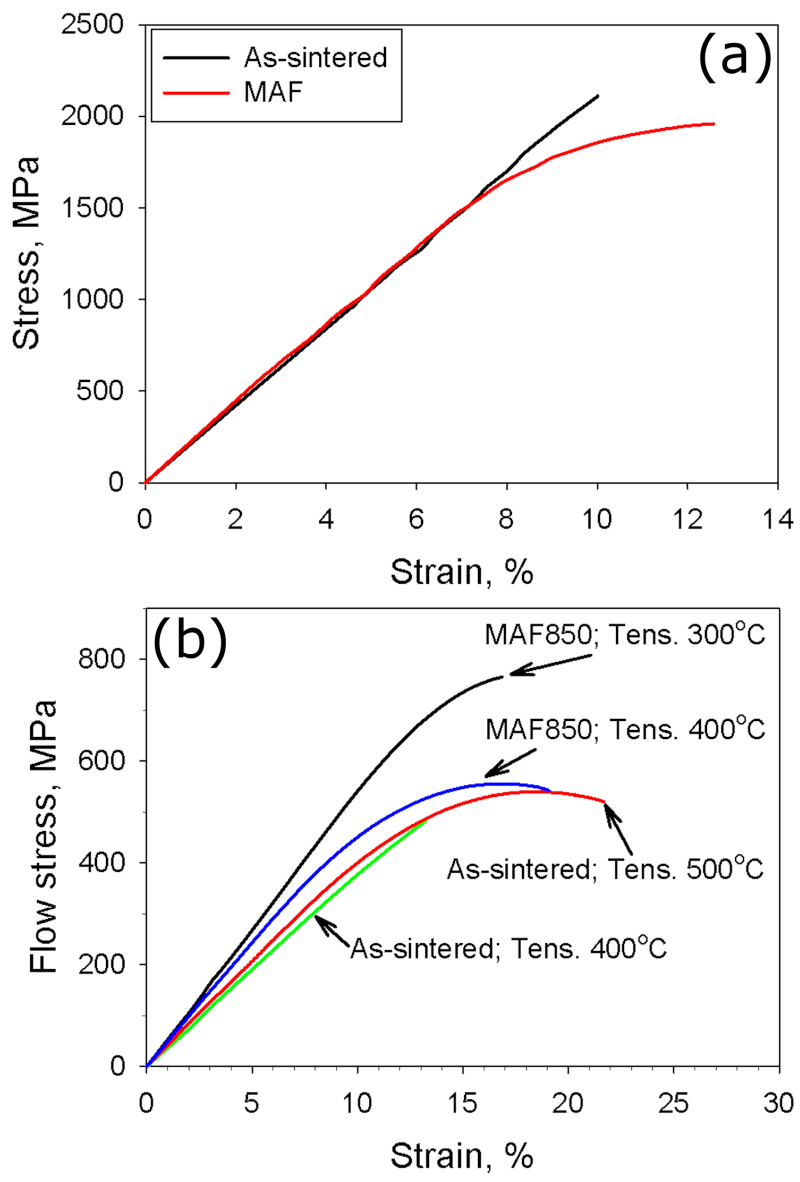

Fig. 5. Stress-strain curves of Ti/TiB MMC in different conditions tested in compression at room temperature (a) or in tension at elevated temperatures (b).

the MAF (Fig. 4) causing, most likely, the corresponding decrease in the flow stress after the first compression (Fig. 2). Since the apparent length of the TiB whiskers did not decrease noticeably with further strain, a stable aspect ratio of $\approx 10$ was achieved. The aspect ratio of the TiB (rather than the diameter) is considered to be the main factor that influences the mechanical properties of the MMCs. It was shown in [11] that whiskers with a large value of aspect ratio make a greater contribution to the strength of the composite. In turn this can be associated with different contribution of various strengthening mechanisms (mainly the Orowan mechanism or hardening due to a load transfer from the Ti matrix to TiB by an interfacial shear stress [12]) depending on the lengthto-diameter ratio. Therefore a stable length-to-diameter ratio after the MAF can result in the observed improvement of strength and ductility in comparison with the as-sintered condition (Fig. 5).

Some difference in the mechanical properties of the MMC after the MAF can also be ascribed to the structure of the Ti matrix. The development of discontinuous dynamic recrystallization in the Ti matrix of the MMC can be proved by the formation of dislocation-free areas 
(Fig. 3b) and characteristic type of the aggregated mechanical behavior with a steady-like flow stage during the MAF at $850^{\circ} \mathrm{C}$ (Fig. 2) [13] and agrees with the previous data [3]. It is known that the presence of recrystallized areas in nanostructured materials enhance their strain hardening capacity and thus promote ductility [14]. In the studied $\mathrm{Ti} / \mathrm{TiB}$ composite, the combination of the recrystallized $\mathrm{Ti}$ grains and the areas with high dislocation density strengthened by the nanosized TiB whiskers provides a good balance of strength and ductility which exceeds the corresponding properties of the as-sintered material.

\section{Conclusions}

1. Mechanical behavior during the MAF at $850{ }^{\circ} \mathrm{C}$ can be described by an aggregated $\sigma-\Sigma \varepsilon$ curves which demonstrated a pronounced softening following by a steady-like state flow. The observed mechanical behavior can be associated with the formation of a stable aspect ratio of $\approx 10$ of the $\mathrm{TiB}$ whiskers during the MAF and development of discontinuous dynamic recrystallization. The MAF resulted in the formation of a homogeneous microstructure with dislocation-free areas of $\approx 1 \mu \mathrm{m}$ and areas with high density of $\mathrm{TiB}$ and high dislocation density.

2. The $\mathrm{MAF}$ at $850^{\circ} \mathrm{C}$ to cumulative strain $\approx 5.2$ resulted in a considerable increase in low-temperature ductility without loss in strength. For instance, nearly zero ductility was obtained in the as-sintered specimen during compression at room temperature, whereas specimens after the MAF demonstrated at this temperature $\approx 3 \%$ ductility.

\section{Acknowledgments}

The work was supported by the Russian Science Foundation under Grant No. 15-19-00165. The authors are also grateful to Joint Research Center "Materials and Technologies", Belgorod State University, for the assistance with instrumental analysis.

\section{References}

[1] T. Saito, T. Furuta, T. Yamaguchi, in: Recent Advances in Titanium Metal Matrix Composites, Eds. F.H. Froes, J. Storer, The Minerals, Metals and Materials Society, Warrendale 1995, p. 33.

[2] L.J. Huang, L. Geng, H-X. Peng, Prog. Mater. Sci. 71, 93 (2015).

[3] M. Ozerov, M. Klimova, A. Kolesnikov, N. Stepanov, S. Zherebtsov, Mater. Des. 112, 17 (2016).

[4] K. Morsi, V.V. Patel, J. Mater. Sci. 42, 2037 (2007).

[5] H. Feng, Y. Zhou, D. Jia, Q. Meng, J. Rao, Cryst. Growth Des. 6, 1626 (2006).

[6] R.A. Gaisin, V.M. Imayev, R.M. Imayev, J. Alloys Comp. 723, 385 (2017).

[7] V. Imayev, R. Gaisin, E. Gaisina, R. Imayev, H.J. Fecht, F. Pyczak, Mater. Sci. Eng. A Struct. 609, 34 (2014)

[8] L.J. Huang, L. Geng, B. Wang, L.Z. Wu, Mater. Des. 45, $532(2013)$.

[9] G.A. Salishchev, S.Yu. Mironov, S.V. Zherebtsov, Rev. Adv. Mater. Sci. 11, 152 (2006).

[10] K.S. Ravi Chandran, K.B. Panda, S.S. Sahay, JOM 56, 42 (2004).

[11] M.Y. Koo, J.S. Park, M.K. Park, K.T. Kim, S.H. Hong, Scr. Mater. 66, 487 (2012).

[12] B. Chen, J. Shen, X. Ye, L. Jia, S. Li, J. Umeda, M. Takahashi, K. Kondoh, Acta Mater. 140, 317 (2017).

[13] F. Humphreys, M. Hatherly, Recrystallization and Related Annealing Phenomena, Elsevier, Oxford 2004.

[14] Y. Wang, M. Cheng, F. Zhou, E. Ma, Nature 419, $912(2002)$. 